\title{
Simulation and Experimental Research into Combined Electrochemical Milling and Electrochemical Grinding Machining of Ti40 Titanium Alloy
}

\author{
Xizhong Wang, Hansong $\mathrm{Li}^{*}$ and Shen Niu \\ College of Mechanical and Electrical Engineering, Nanjing University of Aeronautics and \\ Astronautics, Nanjing, 210016, China \\ "E-mail: hsli@nuaa.edu.cn
}

doi: $10.20964 / 2020.11 .09$

Received: 18 October 2019 / Accepted: 21 August 2020 / Published: 30 September 2020

Ti40 titanium alloy is a typical difficult-to-cut material with high tensile strength and toughness. To achieve both high efficiency and high precision, this paper proposes a machining method combining electrochemical milling for rough machining and electrochemical grinding (ECG) for finish machining. Instead of the conventional tool used in electrochemical milling, which has a sharp edge, the tool used had a rounded corner, which increases machining efficiency. The simulation shows that the current density for this tool is weaker at the corner of the machined slot. Slots were cut via rough machining by electrochemical milling. The polarization and current efficiency for Ti40 titanium alloy in $10 \mathrm{wt} \%$ NaNO3 electrolyte were measured. The experimental results show that the maximum feeding rate for electrochemical milling of Ti40 increased from 1.5 to $1.7 \mathrm{~mm} / \mathrm{min}$. The cuts were $3 \mathrm{~mm}$ deep and the material removal rate was $21.2 \mathrm{~mm}^{3} \mathrm{~min}^{-1}$. The sidewalls of the machined slots were finished with ECG. Only a small amount of material was removed and there was no overcut. The average sidewall flatness and surface roughness decreased from 109.7 to $59.0 \mu \mathrm{m}$ and from 5.089 to $0.789 \mu \mathrm{m}$. The oxidation film formed during the rough machining had been removed.

Keywords: Ti40 titanium alloy; Electrochemical milling; Electrochemical grinding; Flatness; Surface roughness

\section{FULL TEXT}

(C) 2020 The Authors. Published by ESG (www.electrochemsci.org). This article is an open access article distributed under the terms and conditions of the Creative Commons Attribution license (http://creativecommons.org/licenses/by/4.0/). 